\title{
UJI STABILITAS FORMULA OPTIMAL SEDIAAN TOPIKAL EKSTRAK BIJI LABU KUNING (Cucurbita Maxima)
}

\author{
Stability Testing Of Pumpkind Seed Extract (Cucurbita Maxima) Optimal \\ Formula In Topical Formulation
}

\author{
Istianatus Sunnah $^{(1)}$, Wening Sri Mulasih ${ }^{(2)}$, Septi Mariani ${ }^{(3)}$, Agitya Resti \\ Erwiyani $^{(4)}$ \\ (1)(2)(3)(4) Program Studi Farmasi Universitas Ngudi Waluyo Ungaran \\ istihizna@yahoo.com
}

\begin{abstract}
Latar belakang: Sediaan topikal antiaging sangat diminati kaum hawa terutama yang mengandung senyawa herbal karena mudah digunakan. Beberapa formula topikal yang masih banyak digunakan antara lain, krim dan masker gel. Labu kuning dan bijinya merupakan salah satu tanaman yaang memiliki antioksidan tinggi dan belum dimanfaatkan sebagai sediaan topikal.

Tujuan: Formula masker gel peel-off dan krim memiliki beberapa bahan tambahan yang akan berpengaruh terhadap kestabilan sediaan. Untuk mengantisipasi hal tersebut, perlu adanya optimasi formula sehingga didapatkan formula optimal yang memiliki stabilitas dalam penyimpanan jangka lama.

Metode : Optimasi formula menggunakan Design Expert dengan parameter stabilitas meliputi daya sebar, daya lekat, viskositas, $\mathrm{pH}$, waktu kering. Pengaruh waktu penyimpanan terhadap parameter stabilitas tersebut diuji menggunakan t-Test dengan taraf kepercayaan $95 \%$.

Hasil : analisa menunjukkan formula optimal masker gel peel-off biji labu kuning lebih stabil dalam penyimpanan tetapi memiliki waktu kering yang cukup lama karena konsnetrasi PVA tidak optimal. Sedangkan sediaan krim biji labu kuning, mengalami perubahan meskipun tidak berbeda signifikan.

Simpulan: Secara umum, formula optimal masker gel peel-off dan krim ekstrak biji labu kuning stabil selama penyimpanan 1 bulan, tetapi memiliki waktu kering yang lama.
\end{abstract}

Kata kunci : Optimasi formula, masker, krim biji labu kuning

\section{ABSTRACT}

Background: Topical antiaging formulation are very popular among women, especially those containing herbal compounds because they are easy to use. Some topical formulas that are still widely used include cream and gel masks. Pumpkin seeds are one of the plants that have high antioxidants and have not been used as topical preparations.

Purpose: The formula of peel-off gel mask and cream has several additives that will affect the stability of the preparation. To anticipate this, formula 
optimization is needed so that an optimal formula that has stability in long-term storage is needed.

Method: Optimization of formulas using Design Expert with stability parameters including spreadability, adhesion, viscosity, $\mathrm{pH}$, dry time. The effect of storage time on stability parameters was tested using t-Test with a confidence level of $95 \%$.

Results: The analysis shows that the optimal formula for peel-off gel pumpkin seeds is more stable in storage but has a long dry time because the PVA concentration is not optimal. While the pumpkin seed cream have change although not significantly different.

Conclusion: In general, the optimal formula of peel-off gel mask and cream of pumpkin seed extract are stable for 1 month storage, but has a long dry time.

Keyword : Formula optimization,mask, cream, pumpkin seeds

\section{PENDAHULUAN}

Dewasa ini, sediaan bahan alam antiaging banyak diminati terutama dalam formula topikal karena lebih mudah untuk diaplikasikan. Bahan alam yang diformulasikan sebagai antiaging umumnya memiliki senyawa metabolit sebagai antioksidan seperti flavonoid dan karotenoid. Salah satu bahan alam yang mengandung senyawa flavonoid dan karotenoid tinggi adalah labu kuning(Šlosár et al., 2018). Daging labu kuning banyak dimanfaatkan sebagai bahan kosmetika. Salah satu penelitian tentang ekstrak daging buah labu kuning, menunjukkan bahwa ekstrak tersebut memiliki aktivitas antioksidan (Rikhana, 2018), dimungkinkan bagian bijinya juga memiliki kandungan antioksidan. Ekstrak biji labu kuning memiliki aktivitas penghambatan radikal bebas serta memiliki kandungan trace elements (Kushawaha et al., 2016). Selama ini biji labu kuning (Cucurbita maxima seeds) belum dimanfaatkan secara maksimal sebagai sediaan farmasi dan hanya untuk sediaan pangan saja. Untuk itu perlu adanya formulasi biji labu kuning sebagai antioksidan terutama dalam formulasi sediaan topikal seperti masker gel peel -off atau krim antiaging. Permasalahan yang umum terjadi pada sediaan topikal antara lain stabilitas selama penyimpanan. Untuk itu perlu adanya optimasi formula menggunakan software Design Expert supaya mendapatkan formula optimal yang stabil selama penyimpanan. Software ini dapat menentukan formula optimal dan interaksi dari berbagai bahan tambahan yang digunakan dalam sediaan tersebut.

Evaluasi formula optimal dilakukan selama penyimpanan sediaan sehingga stabilitas sediaan terjaga. Hal ini dilakukan karena stabilitas sediaan yang menurun akan mempengaruhi efektivitas dari formula. Stabilitas sediaan yang mengalami penurunan, akan mempengaruhi stabilitas senyawa metabolit yang terkandung didalamnya, sehingga berpengaruh terhadap efektivitas dan penetrasi senyawa metabolit ke dalam kulit. 


\section{METODE PENELITIAN}

Alat penelitian

Alat -alat gelas, rotary evaporator, gelas ukur, mortir, stamper, cawan petri, blender, oven, pipet tetes, batang pengaduk, spatula, $\mathrm{pH}$ meter, objek glass, viskometer brookfield, alat ukur daya lekat, alat ukur daya sebar Bahan penelitian

Formula krim ekstrak biji labu kuning (EBLK) :

Ekstrak biji labu kuning,setil alkohol, stearil alkohol, isopropil miristat, propilenglikol, tween 80 , metil paraben, propil paraben, span 80 , aquadest.

Formula masker gel peel off ekstrak biji labu kuning :

Ekstrak biji buah labu kuning (Cucurbita maxima), polyvinyl alcohol (PVA), hidroxypropyl methylcelullosa (HPMC), propilenglikol, metil paraben, propil paraben, asam sitrat, aquades.

Tahapan penelitian

a. Pembuatan EBLK :

Simplisia biji labu kuning yang telah dikeringkan, dimaserasi menggunkan n-Heksan selama 3 hari, kemudian filtrat yang diperoleh dipekatkan menggunakan rotary evaporator.

b. Optimasi Formula masker peel off EBLK

Formula masker gel peel off EBLK dioptimasi menggunakan software Design Expert dengan konsentrasi bahan yang dioptimasi PVA 6-9\% dan HPMC $1-4 \%$.

c. Pembuatan Formula masker gel peel off EBLK

PVA dan HPMC dikembangkan secara terpisah dalam cawan porselin yang diberi aquades panas diatas waterbath sampai jernih mengembang. Kemudian ditambahkan asam sitrat 0,1 g dalam larutan PVA. Setelah mengembang ekstrak ditambahkan pada basis HPMC, metil paraben dan propil paraben dilarutkan dalam propilenglikol, dan semua bahan dicampurkan secara homogen dan ditambahkan EBLK 0,625\%.

d. Optimasi Formula krim EBLK

Optimasi dilakukan dengan menggunakan software Design Expert, dengan bahan yang dioptimasi Isopropil miristat 1-4 \% dan propilenglikol 16-19\%.

e. Pembuatan Formula krim EBLK

Fase minyak yang terdiri dari stearil alkohol, setil alkohol, span 80, isopropyl miristat dan terakhir propil paraben, dilebur pada waterbath dengan suhu $70^{\circ} \mathrm{C}$. Fase air yaitu propilen glikol, tween 80 , metil paraben dan $3 / 4$ aquadest, dilebur pada waterbath dengan suhu $70^{\circ} \mathrm{C}$. Kemudian kedua fase tersebut dcampur secara homogen dengan stirer dengan kecepatan 800 rpm.dan ditambahkan ekstrak biji labu kuning (Cucurbita maxima) sedikit demi sedikit. f. Uji Sifat Fisik dan stabilitas formula krim dan masker gel peel off EBLK

Uji sifat fisik tiap formula yang dilakukan meliputi uji organoleptis, uji homogenitas, uji daya sebar, uji daya lekat, uji viskositas, uji $\mathrm{pH}$ dan uji waktu kering untuk masker gel peel off EBLK selama penyimpanan 1 bulan 
g. Analisa data

Untuk menganalisa adanya perubahan penyimpanan selama 1 bulan pada suhu kamar, hasilnya dianalisis menggunakan uji $\mathrm{T}$ dengan taraf kepercayaan $95 \%$.

\section{HASIL DAN PEMBAHASAN}

\section{Ekstraksi biji labu kuning}

Ekstraksi biji labu kuning menggunakan pelarut n-Heksan yang bersifat non polar dengan tujuan dapat mengekstraksi senyawa metabolit flavonoid dan karotenoid yang memiliki aktivitas antioksidan sehingga formula topikal tersebut diharapkan memiliki aktivitas antioksidan yang tinggi. Bobot simplisia biji labu kuning yang digunakan sebanyak $350 \mathrm{~g}$ diperoleh hasil evaporasi berupa ekstrak kental sebanyak 93,4 g sehingga rendemen yang diperoleh sebesar 26,69\%. Semakin banyak ekstrak yang tersari, kandungan senyawa metabolit cukup banyak terdapat di dalamnya (Kartikasari et al., 2008)

\section{Formula optimal masker peel off EBLK}

Komposisi formula masker peel off EBLK terdiri dari ekstrak, PVA, HPMC, propilenglikol, metil paraben,propil paraben dan air. PVA dan HPMC sebagai bahan tambahan dioptimasi supaya mampu memberikan kestabilan yang baik selama penyimpanan suhu ruang dengan parameter daya sebar, daya lekat, viskositas, pH dan waktu kering. PVA dan HPMC berfungsi sebagai bahan untuk meningkatkan viskositas pada sediaan topikal (Rowe, Sheskey, \& Quinn, 2009) sehingga pada penyimpanan dalam jangka waktu panjang, sediaan topikal masker peel off tetap memiliki kekentalan yang baik. Berdasarkan hasil optimasi menggunakan metode $D$ - optimal diperoleh formula optimal seperti pada tabel (1).

Tabel 1. Formula optimal peel off EBLK

\begin{tabular}{lc}
\hline \multicolumn{1}{c}{ Bahan } & Konsentrasi (\%) \\
\hline EBLK & $\mathbf{1}$ \\
PVA & 7,606 \\
HPMC & 2,394 \\
Propilenglikol & 12 \\
Metil paraben & 0,2 \\
Propil paraben & 0,06 \\
Aquades & Ad 100 \\
\hline
\end{tabular}

\section{Formula optimal krim EBLK :}

Sediaan krim EBLK diperoleh dengan melakukan optimasi komposisi isopropil miristat dan propilenglikol. IPM berfungsi sebagai enhancer penetration supaya senyawa metabolit flavonoid dan karotenoid sebagai antioksidan yang terkandung dalam biji labu kuning, mampu tertransport ke dalam kulit. Propilenglikol berfungsi sebagai stabilizing agent dan humectant pada formulasi topikal (Rowe et al., 2009). Hasil optimasi menggunakan metode D-optimal pada sediaan krim diperoleh hasil seperti pada tabel (2). 
Tabel 2. Formula optimal krim EBLK

\begin{tabular}{lc}
\hline \multicolumn{1}{c}{ Bahan } & Konsentrasi (\%) \\
\hline EBLK & 1 \\
Setil alcohol & 2 \\
Isopropil miristat & 3,692 \\
Propilen glikol & 16,308 \\
Tween 80 & 1.5 \\
Nipagin & 0,1 \\
Nipasol & 0,1 \\
Span 80 & 2 \\
Stearil Alkohol & 8 \\
Aquadest & Ad 100 \\
\hline
\end{tabular}

Uji sifat fisik dan stabilitas formula masker gel peel off dan krim EBLK a. Uji organoleptis dan homogenitas

Pemeriksaan organoleptis sediaan dilakukan dengan pengamatan karakteristik secara visual meliputi bentuk, warna,bau, konsistensi dan homogenitas dari formula (Niazi, 2004). Homogenitas formula sangat diperlukan dalam pengujian sediaan karena efektifitas sediaan ditentukan dari formula yang homogen (Andriani \& Pratimasari, 2018). Hasil uji organoleptis kedua formula menunjukkan tidak terjadi perubahan selama penyimpanan 1 bulan. Krim tetap berbentuk setengah padat, warna putih dan bau khas ekstrak sedangkan masker peel gel peel off EBLK berwarna jernih, berbentuk semi padat, bau khas ekstrak. Selama penyimpanan, kedua sediaan tersebut tetap homogen dan komposisi bahan terdistribusi merata ( Tabel 3 dan 4). Hal ini dibuktikan pada saat uji homogenitas dengan mengoleskan formula di atas permukaan lempeng kaca, tidak ditemukan adanya butiran kasar yang tampak.

Tabel 3. Uji organoleptis dan homogenitas sediaan masker gel peel off EBLK

\begin{tabular}{lccccc}
\hline & \multicolumn{5}{c}{ organoleptis masker gel peel off EBLK } \\
\cline { 2 - 6 } & Minggu & Minggu ke- & Minggu & Minggu & Minggu \\
& ke-0 & $\mathbf{1}$ & ke-2 & ke-3 & ke-4 \\
\hline Bentuk & semi padat & semi padat & semi padat & semi padat & semi padat \\
& khas & khas & khas & khas & khas \\
Bau & ekstrak & ekstrak & ekstrak & ekstrak & ekstrak \\
Warna & putih & putih & putih & putih & putih \\
Homogenitas & + & + & + & + & + \\
\hline
\end{tabular}


Tabel 4. Uji organoleptis dan homogenitas sediaan krim EBLK

\begin{tabular}{lccccc}
\hline & \multicolumn{5}{c}{ Organoleptis krim EBLK } \\
\cline { 2 - 6 } & $\begin{array}{c}\text { Minggu } \\
\text { ke-0 }\end{array}$ & $\begin{array}{c}\text { Minggu ke- } \\
\text { Minggu }\end{array}$ & $\begin{array}{c}\text { Minggu } \\
\text { ke-2 }\end{array}$ & $\begin{array}{c}\text { Minggu } \\
\text { ke-3 }\end{array}$ & ke-4 \\
\hline Bentuk & semi padat & semi padat & semi padat & semi padat & semi padat \\
& tidak & tidak & tidak & tidak & tidak \\
Bau & berbau & berbau & berbau & berbau & berbau \\
Warna & putih & putih & putih & putih & putih \\
Homogenitas & + & + & + & + & + \\
\hline
\end{tabular}

\section{b. Uji daya sebar}

Daya sebar sediaan sangat mempengaruhi efektivitas dari formula karena kemampuan basis untuk menyebar merata di permukaan kulit akan mempermudah pemerataan sediaan dan zat aktif sehingga efektivitas zat aktif akan semakin optimal (Shovyana \& Zulkarnain, 2013). Hasil uji normalitas daya sebar kedua formula menunjukkan bahwa nilai $\mathrm{p}>0,05$, maka data terdistribusi normal. Uji daya sebar sediaan masker gel peel-off EBLK yang dilakukan tiap minggu selama 1 bulan menunjukkan bahwa terjadi penurunan daya sebar tetapi berdasarkan $t$-test, penyimpanan selam 1 bulan pada suhu ruang tidak memberikan perbedaan yang bermakna terhadap daya sebar tersebut tabel (3). Demikian juga halnya dengan sediaan krim EBLK, yang menunjukkan adanya penurunan daya sebar, tetapi tidak memberikan perbedaan pada pengujian tiap minggu. Terbukti bahwa daya sebar kedua formula tersebut masih berada dalam rentang yang dipersyaratkan $5-7 \mathrm{~cm}$ (Garg,et al., 2002).

\section{Tabel 5. Uji daya sebar sediaan masker peel off dan krim EBLK selama penyimpanan}

\begin{tabular}{lccccc}
\hline \multirow{2}{*}{ Formulasi } & \multicolumn{5}{c}{ daya sebar $(\mathbf{c m})$} \\
\cline { 2 - 6 } & M0 & M1 & M2 & M3 & M4 \\
\hline Pell off & & & & $5.5625 \pm 0.1$ \\
EBLK & $5.69 \pm 0.260$ & $5.745 \pm 0.31$ & $5.675 \pm 0.18$ & $5.675 \pm 0.25$ & 9 \\
Krim EBLK & $6.56 \pm 0.125$ & $6.31 \pm 0.24$ & $5.22 \pm 0.25$ & $5.0 \pm 0$ & $5.06 \pm 0.13$ \\
\hline
\end{tabular}

\section{c. Uji daya lekat}

Pengujian daya lekat dimaksudkan supaya sediaan topikal memiliki waktu perlekatan yang lebih lama dan mencapai aktivitas sesuai yang diinginkan. Daya lekat sediaan masker gel peel off EBLK lebih lama dibandingkan dengan sediaan krim karena basis formula masker gel peel off EBLK mengandung HPMC. Karakteristik HPMC mampu menyerap cairan yang terdapat dalam formula, menyebabkan konsistensi formula menjadi lebih kental, dan sediaan melekat lebih lama. Hal ini akan berbanding terbalik dengan daya sebar, karena HPMC yang digunakan semakin banyak, maka viskositasnya semakin besar, sediaan semakin kental dan memiliki daya sebar yang lebih sempit (Arikumalasari, Dewantara, \& Wijayanti, 2013). Daya lekat pada kedua 
formula tersebut menunjukkan terjadi penurunan daya lekat tetapi tidak signifikan pada tiap minggu setelah penyimpanan selama 1 bulan.

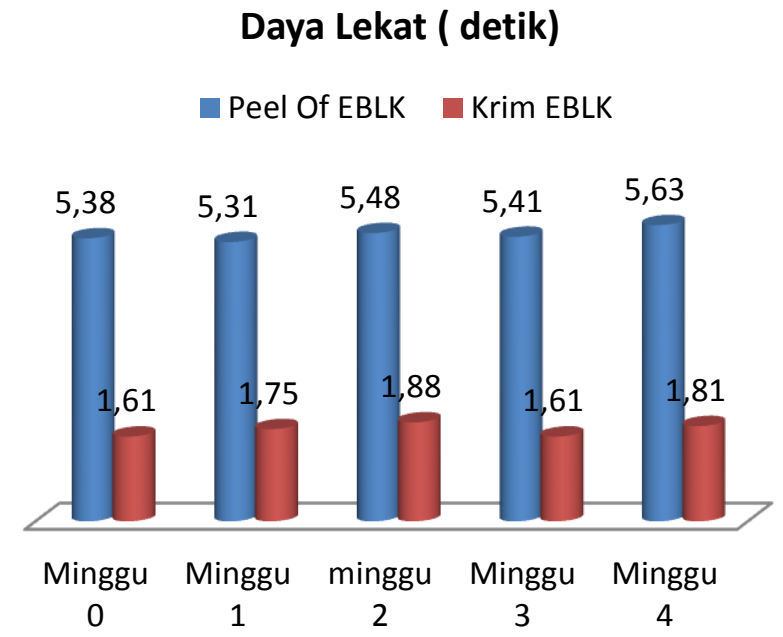

Gambar 1 . Daya lekat sediaan masker gel peel off dan krim EBLK selama penyimpanan dalam 1 bulan

\section{d. Uji Viskositas}

Pengukuran viskositas sediaan masker gel peel-off dan krim EBLK menggunakan viskosimeter Brookfield. Berdasarkan hasil pengujian diperoleh data bahwa viskositas sediaan masker gel peel-off EBLK memiliki kestabilan viskositas yang lebih baik saat penyimpanan pada suhu ruang selama satu bulan dibandingkan dengan sediaan krim EBLK (gambar 2). Hal yang mempengaruhi dari kestabilan viskositas sediaan masker peel off adalah kombinasi PVA dan HPMC (Rowe et al., 2009). HPMC memiliki sifat yang mampu meningkatkan viskositas dari sediaan topikal. Adanya penambahan PVA, memberikan interaksi yang sinergis terhadap peningkatan kekentalan formula, seperti yang tergambar dalam hasil optimasi pada gambar 3 .

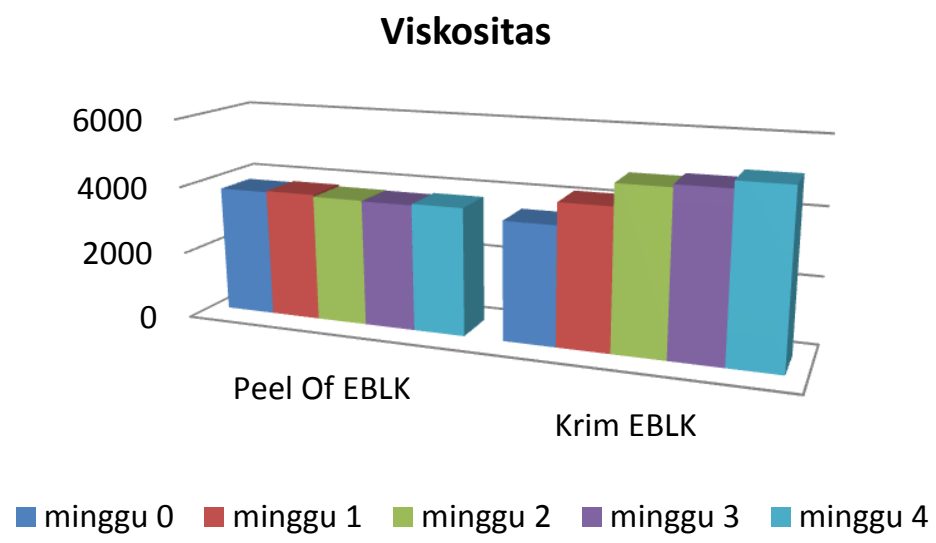

Gambar 2. Diagram pengaruh penyimpanan terhadap viskositas masker gel peel -off dan krim Ekstrak Biji Labu Kuning

Uji Stabilitas Formula Optimal Sediaan Topikal Ekstrak Biji Labu Kuning (Cucurbita Maxima) (Istianatus Sunnah, Wening Sri Mulasih, Septi Mariani, Agitya Resti Erwiyani) 
Formula krim EBLK mengalami peningkatan viskositas saat penyimpanan selama 1 bulan. Peningkatan viskositas pada sediaan krim EBLK, dipengaruhi oleh konsentrasi propilenglikol yang tinggi dan optimal pada konsentrasi $16,308 \%$. Konsistensi propilenglikol yang kental dan bersifat sebagai humectant dengan sifat higroskopis paling rendah, dengan adanya penyimpanan jangka lama akan meningkatkan viskositas sediaan. Humectan berfungsi sebagai penstabil kelembapan pada sediaan selama disimpan maupun diaplikasikan sehingga konsistensi krim selalu terjaga. Fungsi propilenglikol sebagai humectant akan mampu menyerap air pada penyimpanan, sehingga menyebabkan konsistensi krim semakin kental (Marlinna, 2007).

\section{e. Uji pH}

Sediaan topikal perlu dilakukan uji $\mathrm{pH}$ untuk meminimalkan respon iritasi saat aplikasi pada kulit. $\mathrm{pH}$ standar yang diperbolehkan untuk sediaan topikal berdasarkan SNI adalah 4,5-8. Selama penyimpanan, sediaan masker gel peel off dan krim EBLK, memiliki persyaratan $\mathrm{pH}$ sesuai dengan standar SNI. Hal ini menunjukkan bahwa, kedua formula optimal EBLK, tidak akan memberikan respon iritasi selama aplikasi pada kulit.

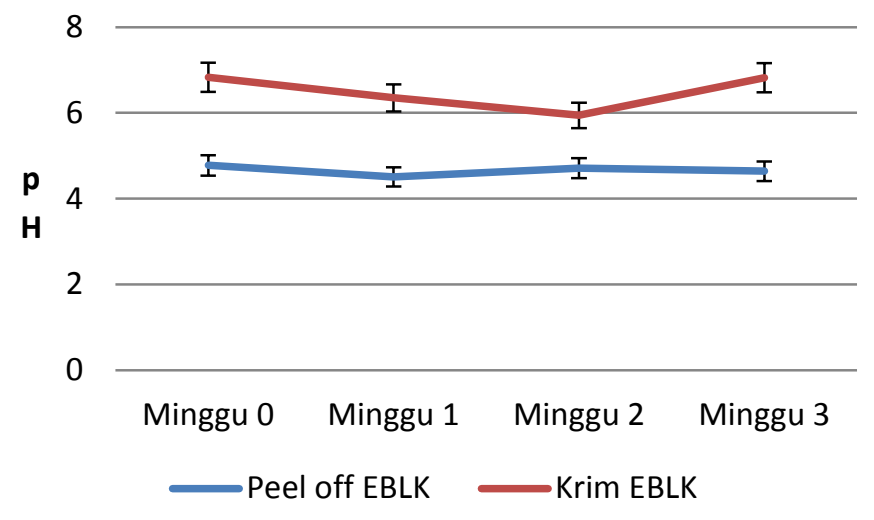

Gambar 3. Diagram uji pH sediaan selama penyimpanan

\section{f. Uji waktu kering masker gel peel-off}

Salah satu persyaratan yang harus dipenuhi oleh sediaan masker gel peel off adalah kemampuan untuk mengering selama aplikasi kulit. Uji waktu kering, dilakukan secara in vivo dengan mengoleskan sediaan pada kulit tangan probandus sebanyak 0,7 gram pada area seluas $5,0 \times 2,5 \mathrm{~cm}$ dan diamati lama waktu pengeringan. Waktu pengeringan masker selama penyimpanan lebih dari 30 menit. Hal ini belum sesuai dengan standar waktu kering sediaan antara 1530 menit. Lama waktu pengeringan masker dipengaruhi oleh konsentrasi PVA yang digunakan. PVA dengan konsentrasi yang tinggi sebagai gelling agent, akan memberikan waktu kering masker gel peel off semakin cepat dan masuk dalam rentang yang dipersyaratkan (Zhelsiana et al., 2016). 
Tabel 5. Waktu kering masker gel peel off selama penyimpanan

\begin{tabular}{lccccc} 
& \multicolumn{5}{c}{ waktu kering ( menit) } \\
\cline { 2 - 6 } Formulasi & $\begin{array}{c}\text { Minggu ke- } \\
0\end{array}$ & $\begin{array}{c}\text { Minggu } \\
\text { ke- } 1\end{array}$ & Minggu ke-2 & Minggu ke-3 & $\begin{array}{c}\text { Minggu } \\
\text { ke-4 }\end{array}$ \\
\hline Pell off & $41.25 \pm 22.17$ & $37 \pm 0.82$ & $36.75 \pm 0.22 .17$ & $34.75 \pm 0.27 .54$ & $3.65 \pm 28.87$ \\
\hline EBLK & & &
\end{tabular}

\section{SIMPULAN DAN SARAN}

\section{Simpulan}

Adanya bahan tambahan pada sediaan formulasi topikal akan mempengaruhi kestabilan selama penyimpanan. Salah satunya adalah komposisi PVA dan HPMC dalam stabilitas fisik meliputi daya sebar, daya lekat, viskositas, $\mathrm{pH}$ dan waktu kering formula optimal masker gel peel-off ekstrak biji labu kuning. Formula optimal masker gel peel-off EBLK, waktu keringnya dipengaruhi oleh PVA. HPMC mempengaruhi daya lekat dan viskositas formula optimal masker. Konsentrasi HPMC tinggi, daya lekat dan viskositas masker gel peel -off ekstrak biji labu kuning semakin besar. Sedangkan konsentrasi PVA yang kurang menyebabkan waktu kering formula optimal masker gel peel- off semakin lama. Propilenglikol mempengaruhi viskositas dan daya lekat formula optimal krim ekstrak biji labu kuning. Viskositas formula optimal krim biji labu kuning mengalami peningkatan selama penyimpanan karena konsentrasi propilenglikol. Secara umum, stabilitas formula optimal masker gel peel-off dan krim ekstrak biji labu kuning stabil dalam penyimpaanan suhu ruang selama 1 bulan, tetapi waktu kering sediaan masker masih belum sempurna.

\section{Saran}

Perlu adanya pengembangan formulasi dengan optimasi berbagai bahan tambahan yang dapat menurunkan waktu kering masker gel peel-off.

\section{DAFTAR PUSTAKA}

Andriani, D., \& Pratimasari, D. (2018). Formulasi Ekstrak Rambut Jagung (Corn Silk Zea Mays) Dalam Krim Tabir Surya Sebagai Preventif Kanker Kulit. Indonesian Journal of Pharmacy and Narural Product, 1(2), 21-27.

Arikumalasari, J., Dewantara, I., \& Wijayanti, N. (2013). Optimasi HPMC Sebagai Gelling Agent Dalam Formula Gel Ekstrak Kulit Buah Manggis ( Garcinia mang0stana L ). Jurnal Farmasi Udayana, 2(3).

Garg, A., Garg, S., \& Singla, A. K. (2002). Spreading of Semisolid Formulations An Update. In Pharmaceutical Technology. 
Kartikasari, D., Pramono, S., Farmasi, F., Ahmad, U., Farmasi, F., Gadjah, U., \& Yogyakarta, M. (2008). Karakterisasi Simplisia dan Ekstrak Etanol daun Bertoni (Stevia reabudiana) dari Tiga Tempat Tumbuh. Universitas Ahmad Dahlan Yogyakarta.

Kushawaha, D. K., Yadav, M., Chatterji, S., Maurya, G. S., Rai, A. K., \& Watal, G. (2016). Free Radical Scavenging Index Of Cucurbita Maxima Seeds And Their Libs Based Antioxidant Elemental Profile Free Radical. International Journal of Pharmacy and Pharmaceutical Sciences, 8(4).

Marlinna. (2007). Optimasi komposisi propilen glikol dan sorbitol sebagai Humectant dalam Formula Krim Hair Loss Ekstrak Saw Palmetto (Sereboa repens): Aplikasi Desain faktorial. Skripsi, Universitas Sanata Dharma Yogyakarta.

Niazi, S. K. (2004). Pharmaceutical Manufacturing Formulations. New York Washington DC: CRC Press.

Rikhana, I. (2018). Uji Antioksidan Ekstrak Daging Buah Labu Kuning (Cucurbita maxima D) Dengan Metode Metal Ion Chelating dan ABTS (2,2 Azinobis (3-Etilbenzotiazolin)-6- Asam Sulfonat). Skripsi, Universitas Ngudi Waluyo.

Rowe, R. C., Sheskey, P. J., \& Quinn, M. E. (Eds.). (2009). Handbook of Pharmaceutical Exipients (Sixth). London,UK: Pharmaceutical Press.

Shovyana, H. H., \& Zulkarnain, A. K. (2013). Stabilitas Fisik Dan Aktivitas Krim W/O Ekstrak Etanolik Buah Mahkota Dewa (Phaleria macrocarph(scheff.) Boerl,) Sebagai Tabir Surya. Traditional Medicine Journal, 18(2), 109-117.

Šlosár, M., Mezeyová, I., Hegedusová, A., \& Hegedus, O. (2018). Quantitative and qualitative parameters in Acorn squash cultivar in the conditions of the Slovak Republic. Potravinarstvo Slovak Journal of Food Sciences, 12(1), 91-98. https://doi.org/10.5219/851

Zhelsiana, D., Pangestuti, Y. ., Nabilla, F., Lestari, N. ., \& ER, W. (2016). Formulasi Dan Evaluasi Sifat Fisik Masker Gel Peel- Off Lempung Bentonite. Universisty Research Colonium, 42-45. 